\title{
CHARAKTERYSTYKA I WYSTĘPOWANIE CYBUTRYNY I TERBUTRYNY W WODACH I ŚCIEKACH
}

\begin{abstract}
W wyniku wdrożenia dyrektywy 2013/39/UE lista substancji priorytetowych uległa rozszerzeniu o 15 nowych związków, w tym biocydy cybutrynę i terbutrynę. Rozszerzony został tym samym zakres substancji, których monitoring musi być obowiązkowo prowadzony przez kraje członkowskie UE. Związki te nie były dotychczas w Polsce objęte zakresem monitoringu wód, stąd uznano za celowe dokonanie przeglądu literaturowego informacji związanych z charakterystyką, zastosowaniem i występowaniem wymienionych substancji w środowisku wodnym w innych krajach. Oba wymienione związki należą do grupy triazyn. Są inhibitorami fotosyntezy. Mimo restrykcji nałożonych na ich stosowanie nadal są wykrywane w środowisku wodnym. Wskazano na przykłady występowania obu związków w wodach powierzchniowych lądowych i w wodach portowych. Zwrócono uwagę na możliwość szerokiego występowania obu związków w Polsce ze względu na ich stosowanie jako dodatków do materiałów elewacji budynków i pokryć dachów.
\end{abstract}

Słowa kluczowe: biocydy, algicydy, herbicydy, środki przeciwporostowe, monitoring wód powierzchniowych.

\section{Wstęp}

W 2013 r. weszła w życie dyrektywa Parlamentu Europejskiego i Rady Europy 2013/39/UE z dnia 12 sierpnia 2013 r., zmieniająca dyrektywy 2000/60/WE oraz 2008/ 105/WE [Dziennik Urzędowy Unii Europejskiej, L 226/1, 24.8.2013]. Istotnym elementem nowej dyrektywy jest zwiększenie liczby substancji priorytetowych z 33 do 48 . Wśród piętnastu nowych substancji priorytetowych są związki o różnorodnym zastosowaniu: substancje zawarte w środkach ochrony roślin, chemikalia przemysłowe, uboczne produkty spalania oraz substancje zawarte w produktach biobójczych (biocydy). Niniejsza praca zawiera omówienie dwóch związków z tej ostatniej grupy: cybutryny (Irgarolu) i terbutryny.

\footnotetext{
${ }^{1}$ Przemysław Kułakowski, Politechnika Krakowska, ul. Warszawska 24, 31-155 Kraków, tel. 12 6282876,p.kulakowski@ vistula.wis.pk.edu.pl
} 
Wymienione związki znalazły się na liście substancji priorytetowych w związku z wymaganiami określonymi w dyrektywie 98/8/WE Parlamentu Europejskiego i Rady z dnia 16 lutego 1998 r., dotyczącej wprowadzania do obrotu produktów biobójczych. Dyrektywa ta ograniczyła możliwość stosowania niektórych preparatów przeciwporostowych w żegludze, w tym cybutryny. Ograniczenia te dotyczyły przede wszystkim małych jednostek pływających (poniżej $25 \mathrm{~m}$ długości). W przypadku większych jednostek możliwe było stosowanie cybutryny do roku 2003. Nie oznacza to jednak całkowitego wyeliminowania tego związku ze środowiska wodnego w Europie ze względu na ruch statków spoza obszaru UE, możliwość jego przenikania do wody z osadów dennych oraz - choć nie ma na ten temat informacji - obrotu Irgarolem poza oficjalnym rynkiem bądź zużywania zapasów.

Cybutryna i terbutryna będą zatem objęte monitoringiem wód, podobnie jak pozostałe substancje priorytetowe. Monitoring cybutryny i terbutryny nie był wcześniej w Polsce prowadzony, dlatego celowe jest dokonanie przeglądu zagadnień związanych z charakterystyką, zastosowaniem i występowaniem wymienionych biocydów.

\section{Cybutryna}

\subsection{Charakterystyka substancji}

Cybutryna (2-metylotio-4-tert-butylamino-6-cyklopropylamino-s-triazyna) jest związkiem chemicznym o wzorze sumarycznym $\mathrm{C}_{11} \mathrm{H}_{19} \mathrm{~N}_{5} \mathrm{~S}$, oznaczonym numerem CAS 28159-98-0. Jej masa cząsteczkowa wynosi 253,37. Cybutryna występuje w postaci białego proszku. Podobnie jak znajdująca się na pierwszej liście substancji priorytetowych atrazyna zaliczana jest do grupy triazyn.

Jest wysoce specyficznym i bardzo efektywnym inhibitorem fotosyntezy. Szczególną efektywność wykazuje w odniesieniu do wyższych roślin, mikrofitobentosu i fitoplanktonu. Cybutryna nie jest dobrze rozpuszczalna w wodzie (7 $\mathrm{mg} \cdot \mathrm{l}^{-1}$ ), stąd zawierające ją powłoki ochronne wykazują znaczną trwałość. Logarytm współczynnika podziału oktanol-woda $\log \mathrm{K}_{\text {ow }}$ wynosi 2,8 .

Wartości stężenia letalnego i stężenia skutecznego $\left(\mathrm{LC}_{50}\right.$ i $\left.\mathrm{EC}_{50}\right)$ cybutryny dla wybranych organizmów wynoszą: Lepomis macrochirus (bass niebieski) $\mathrm{LC}_{50}$ (4 dni) $2600 \mathrm{ng} \cdot \mathrm{l}^{-1}$, Oncorhynchus mykiss (pstrąg tęczowy) $\mathrm{LC}_{50}$ (4 dni) 750 $\mathrm{ng} \cdot \mathrm{l}^{-1}$, Lemna gibba (rzęsa garbata) $\mathrm{EC}_{50}(5 \mathrm{dni}) 1650 \mathrm{ng} \cdot 1^{-1}$, Chlorococcum (zielenice) $\mathrm{EC}_{50}(5 \mathrm{dni}) 420 \mathrm{ng} \cdot \mathrm{l}^{-1}$, Navicula pelliculosa (lodzik) (5 dni) $136 \mathrm{ng} \cdot \mathrm{l}^{-1}$, Porphyra yezoensis (szkarłatnice) $\mathrm{EC}_{50}(4 \mathrm{dni}) 600 \mathrm{ng} \cdot \mathrm{l}^{-1}$, Anabaena flos-aquae (sinice) $\mathrm{EC}_{50}(5 \mathrm{dni}) 1900 \mathrm{ng} \cdot \mathrm{l}^{-1}$, Daphnia magna (rozwielitki) $\mathrm{EC}_{50}(2 \mathrm{dni}) 5300$ $\mathrm{ng} \cdot \mathrm{l}^{-1}[4,12,13,14,15,16,19,23]$. 


\subsection{Synonimy}

Cybutryna występuje na rynku pod wieloma nazwami handlowymi: Cybutrin, Cybutryne, Irgarol, Irgarol ${ }^{\circledR} 1051$, Irgarol ${ }^{\circledR}$ 1071, Nuocide 1051, Cybutryne [iso], Einecs 248-872-3, Irgaguard A 2000, Irgaguard D 1071®, Irgaguard ${ }^{\circledR}$ B 5000, Irgaguard® B 5120, Irgaguard ${ }^{\circledR}$ B 6000, Irgaguard® H 6000, Fintryn.

Produkty oznaczone liczbą 1051 stosowane są do pokrywania kadłubów statków, natomiast liczba $1071 \mathrm{w}$ nazwie produktu wskazuje na zastosowanie w budownictwie lądowym.

\subsection{Zastosowanie}

Cybutryna jest algicydem o dwóch podstawowych zastosowaniach:

- $\mathrm{w}$ żegludze i budownictwie wodnym jako dodatek do farb przeciwporostowych w celu zapobiegania porostom na podwodnych częściach budowli wodnych i kadłubów statków,

- w budownictwie do ochrony zewnętrznych części budynków (fasad i dachów) i innych konstrukcji przed rozwojem alg i grzybów.

Cybutrynę zaczęto stosować na szeroką skalę do ochrony kadłubów okrętowych w połowie lat osiemdziesiątych dwudziestego wieku jako substytut tributylocyny (TBT) w związku z udowodnioną szkodliwością tego związku cynoorganicznygo dla wielu organizmów wodnych. Do tego samego celu mogą być stosowane inne także związki, na przykład diuron, dichlorofluanid, czy tolilofuanid.

\section{4. Środowiskowe normy jakości}

Środowiskowe normy jakości wód powierzchniowych w odniesieniu do cybutryny są następujące:

- wody powierzchniowe śródlądowe:

- średnia roczna (AA-EQS) 2,5 ng.1-1,

- maksymalne dopuszczalne stężenie (MAC-EQS) $16 \mathrm{ng} \cdot 1-1$;

- inne wody:

- średnia roczna (AA-EQS) $2,5 \mathrm{ng} \cdot \mathrm{l}^{-1}$,

- maksymalne dopuszczalne stężenie (MAC-EQS) $16 \mathrm{ng} \cdot \mathrm{l}^{-1}$.

\subsection{Występowanie w wodach i ściekach}

Występowanie Irgarolu należy wiązać głównie z wodami o znacznym ruchu jednostek pływających, a więc z wodami przybrzeżnymi, w tym szczególnie wodami portowymi. W literaturze można znaleźć wiele informacji na ten temat.

Stężenie Irgarolu w tych wodach w różnych miejscach świata wynosi od kilkudziesięciu do kilkuset ng $\cdot \mathrm{l}^{-1}$. Wyjątkiem od tego zakresu są wody portowe i przybrzeżne Singapuru, w których stężenie Irgarolu wyniosło $4200 \mathrm{ng} \cdot 1^{-1}$. 
Również wysokie stężenie tego biocydu, przekraczające $1000 \mathrm{ng} \cdot \mathrm{l}^{-1}$, oznaczono w niektórych portowych i przybrzeżnych wodach japońskich [17].

Sezonowe zmiany stężenia Irgarolu 1051 badano w dużym porcie jachtowym w Brighton [3]. Oznaczone wartości stężenia Irgarolu 1051 wahały się w zakresie $<1-960 \mathrm{ng} \cdot \mathrm{l}^{-1}$. Najwyższe wartości obserwowano między listopadem i styczniem, co może być tłumaczone wykonywaniem w tym okresie prac remontowych i konserwacyjnych jachtów. Wysokie wartości stężenia Irgarolu stwierdzono również przed sezonem, co wynikało z prowadzenia w tym czasie prac związanych z nakładaniem na powierzchnie kadłubów nowych warstw farb przeciwporostowych. Zaobserwowano także wyraźny wzrost stężenia Irgarolu w wodzie podczas pogłębiania basenów portowych. Było to związane z zakłóceniem stabilności osadu dennego i przejściem odłożonego tam Irgarolu do fazy wodnej.

Przedstawiony wyżej zakres wartości stężenia Irgarolu w wodzie portu jachtowego w Brighton można uznać za typowy dla tego rodzaju wód, czego dowodzą wyniki badań prowadzonych w marinach angielskich, francuskich, niemieckich i szwedzkich $[1,8,11,21,22,25,29,30,35]$. Podczas badań prowadzonych w kalifornijskich portach jachtowych oznaczono wartości stężenia Irgarolu w zakresie $1,45-339 \mathrm{ng} \cdot \mathrm{l}^{-1}$ [13].

Zwrócono uwagę na wpływ intensywności wymiany wody w strefie przybrzeżnej na wyniki oznaczeń Irgarolu w niemieckich portach jachtowych. Oznaczone wartości stężenia Irgarolu w marinach bałtyckich wynosiły od 80 do 440 ng. $\mathrm{l}^{-1}$, podczas gdy w marinach położonych na wybrzeżu Morza Północnego wahały się w granicach $11-170 \mathrm{ng} \cdot \mathrm{l}^{-1}$. Powiązano to z charakterystyką Morza Bałtyckiego jako morza zamkniętego o ograniczonej wymianie wody [1].

Prowadzono również badania zawartości Irgarolu w estuariach kilu rzek [11, 27, 35]. Zakres oznaczonych wartości stężenia okresie letnim wyniosły:

- estuarium rzeki Hamble, W. Brytania 12-190 $\mathrm{ng} \cdot \mathrm{l}^{-1}$, średnio $84 \mathrm{ng} \cdot 1^{-1}$,

- estuarium rzeki Humber, W. Brytania $<1-39 \mathrm{ng} \cdot \mathrm{l}^{-1}$, średnio $9 \mathrm{ng} \cdot \mathrm{l}^{-1}$,

- estuarium rzeki Medway, W. Brytania 4-18 $\mathrm{ng} \cdot \mathrm{l}^{-1}$, średnio $11 \mathrm{ng} \cdot \mathrm{l}^{-1}$.

W okresie wiosennym w zachodnim estuarium rzeki Skaldy w Holandii 2 $10 \mathrm{ng} \cdot l^{-1}$, średnio $6 \mathrm{ng} \cdot l^{-1}$.

Cytowane wyżej prace dotyczące obszaru Europy w części dotyczą okresu sprzed roku 2000, gdy stosowanie Irgarolu nie było prawnie ograniczone. Nie należy jednak z tego wnosić, że problem obecności tego biocydu w wodach powierzchniowych został całkowicie rozwiązany. Analiza porównawcza wykonana na podstawie badań wykonanych przed rokiem 2000 oraz w roku 2004 w portach jachtowych w Shoreham i w Brighton w Wielkiej Brytanii wykazała, że jakkolwiek w tym okresie nastąpiło znaczące obniżenie stężenia Irgarolu w wodach wymienionych portów, to jednak nadal utrzymywało się ono na poziomie od kilku do ok. $30 \mathrm{ng} \cdot \mathrm{l}^{-1}[10]$.

Niższe wartości cybutryny oznaczono w ostatnio prowadzonych badaniach w wodach duńskich. Najwyższą wartość wynoszącą $13 \mathrm{ng} \cdot \mathrm{l}^{-1}$ zanotowano w por- 
cie kopenhaskim w pobliżu miejsca wodowania jednostek. W żadnym z badanych punktów nie stwierdzono przekroczenia maksymalnego dopuszczalnego stężenia (MAC-EQS), jednak w trzech przypadkach przekroczone były roczne wartości średnie, w tym w dwóch przypadkach w wodach portowych [10].

Ze względu na dodawanie cybutryny do materiałów pokrywających fasady budynków oraz membran bitumicznych stosowanych do pokrycia dachów związek ten może być obecny w ściekach miejskich. Mimo słabej rozpuszczalności cybutryny w przypadku kontaktu materiału elewacji bądź materiału pokrycia dachu $\mathrm{z}$ wodą opadową dochodzi do wymywania środków przeciwporostowych.

Badania przeprowadzone w Szwajcarii wykazały, że zjawisko wymywania biocydów jest szczególnie intensywne w pierwszym okresie po wybudowaniu budynku lub odnowieniu elewacji względnie dachu, później następuje stabilizacja stężenia eluowanych związków. Początkowe wartości stężenia cybutryny w odpływie z fasad zraszanych deszczem wyraża się w setkach $\mu \mathrm{g} \cdot \mathrm{l}^{-1}$, a nawet $\mathrm{w} \mathrm{mg} \cdot \mathrm{l}^{-1}$. Po około czterech latach wartości stężenia cybutryny $\mathrm{w}$ odpływie są o trzy rzędy niższe $[5,6,7,26]$.

\section{Terbutryna}

\subsection{Charakterystyka substancji}

Terbutryna (2-metylotio-4-etyloamino-6-tert-butyloamino-s-triazyna) jest związkiem chemicznym o wzorze sumarycznym $\mathrm{C}_{10} \mathrm{H}_{19} \mathrm{~N}_{5} \mathrm{~S}$, oznaczonym numerem CAS 886-50-0. Masa cząsteczkowa terbitryny wynosi 241,36. Terbutryna występuje w postaci białego lub bezbarwnego proszku. Podobnie jak omówiona w rozdziale 2 cybutryna i znajdująca się na pierwszej liście substancji priorytetowych atrazyna zaliczana jest do grupy triazyn.

Rozpuszczalność terbutryny w wodzie wynosi $25 \mathrm{mg} \cdot \mathrm{l}^{-1}$, jest więc nieco wyższa niż cybutryny. Logarytm współczynnika podziału oktanol-woda $\log \mathrm{K}_{\mathrm{ow}}$ jest równy 3,74 .

Terbutryna jest umiarkowanie toksyczna dla zwierząt. $\mathrm{LD}_{50}$, w przypadku szczurów wynosi $2450-2500 \mathrm{mg} \cdot \mathrm{kg}^{-1}$ masy ciała i $3884 \mathrm{mg} \cdot \mathrm{kg}^{-1}$ masy ciała w przypadku myszy [2]. Wartość $\mathrm{LC}_{50}(8 \mathrm{dni}) \mathrm{w}$ przypadku bażantów wynosi $>20000 \mathrm{mg} \cdot \mathrm{kg}^{-1}$ masy ciała i $4640 \mathrm{mg} \cdot \mathrm{kg}^{-1}$ masy ciała w przypadku kaczki krzyżówki [28,32].

Terbutryna jest również umiarkowanie toksyczna dla ryb. Wartości $\mathrm{LC}_{50}(96$ godzin) wynoszą $3 \mathrm{mg} \cdot \mathrm{kg}^{-1}$ masy ciała dla pstrąga tęczowego i $4 \mathrm{mg} \cdot \mathrm{kg}^{-1}$ masy ciała dla karpia, okonia i bassa niebieskiego [28].

Terbutryna nie jest toksyczna dla pszczół [28].

\subsection{Synonimy}

Terbutryna występuje w produktach handlowych o następujących nazwach: Clarosan, GS 14260 , HS-14260 , Igran, Igran 50 , Igran 500, Prebane, Short- 
Stop, Terbuteryne, Terbutrex, Terbutrin, Terbutrina, Terbutryn, Terbutryn (ANSI), Terbutryn, Terbutryne, Plantonit, Gesaprim Combi (mieszanina z atrazyną 1:1), Igrater 50WP (mieszanina $z$ metobromuronem 1:1), Athado, Senate ( $\mathrm{z}$ trietazyną).

\subsection{Zastosowanie}

Terbutrynę stosowano głównie jako selektywny herbicyd w celu ochrony upraw zbóż, roślin strączkowych i drzew owocowych. Stosowano ją również do ochrony zbiorników wodnych przed zarastaniem zarówno przez rośliny podwodne, jak i pływające [33]. W latach 1995 - 2002 terbutryna (wraz z terbutyloazyną) była jednym z najczęściej stosowanych w Polsce herbicydów do ochrony upraw ziemniaków [31].

Podobnie jak cybutryna znajduje zastosowanie do ochrony przed zarastaniem elementów budowli (fasad i dachów).

\section{4. Środowiskowe normy jakości}

Środowiskowe normy jakości wód powierzchniowych w odniesieniu do terbutryny są następujące:

- wody powierzchniowe śródlądowe

- średnia roczna (AA-EQS) $65 \mathrm{ng} \cdot \mathrm{l}^{-}$

- maksymalne dopuszczalne stężenie (MAC-EQS) $340 \mathrm{ng} \cdot \mathrm{l}^{-}$

- inne wody

- średnia roczna (AA-EQS) $6,5 \mathrm{ng} \cdot \mathrm{l}^{-}$

- maksymalne dopuszczalne stężenie (MAC-EQS) $34 \mathrm{ng} \cdot \mathrm{l}^{-}$

\subsection{Występowanie w wodach i ściekach}

Terbutryna od roku 2003 nie jest stosowana w rolnictwie, znajduje jednak zastosowanie $\mathrm{w}$ budownictwie jako środek zabezpieczający przed porastaniem fasad i dachów budynków.

Mimo wycofania terbutryny z zastosowania rolniczego nadal występuje ona w wodach powierzchniowych. Wykazały to badania wód rzecznych w Hesji (Niemcy), w których kilka lat po wprowadzeniu zakazu stosowania terbutryny nadal oznaczano wysokie wartości jej stężenia, wynoszące aż do $5600 \mathrm{ng} \cdot l^{-1}$ w rzece Weschnitz. Zaobserwowano przy tym wyższe wartości podczas lata niż w zimie, co wskazuje na pochodzenie rolnicze oznaczanej terbutryny. Co istotne, nie następowało obniżanie stężenia terbutryny w wodach powierzchniowych w miarę upływu lat. Niezależnie od tego stwierdzono wysoką zawartość terbutryny w ściekach, zatem i to źródło zanieczyszczenia musi być brane pod uwagę [21]. 
Wysoką wartość stężenia terbutryny kilka lat po wprowadzenie zakazu jej stosowania, wynoszącą $500 \mathrm{ng} \cdot \mathrm{l}^{-1}$, stwierdzono w rzece Ebro w Hiszpanii [20].

$\mathrm{W}$ trakcie najnowszych badań prowadzonych $\mathrm{w}$ duńskich wodach śródlądowych i przybrzeżnych stwierdzono we wszystkich pobranych próbkach wartości stężenia terbutryny niższe niż dopuszczalne, a w niektórych przypadkach zbliżone do nich. Najwyższe stężenie terbutryny, wynoszące $14 \mathrm{ng} \cdot \mathrm{l}^{-1}$ wystąpiło w wodzie jeziora Slagelse. W tym przypadku jako przyczynę wskazano ścieki z oczyszczalni, odprowadzane do jeziora

Należy zwrócić uwagę na zróżnicowany czas połowicznego rozpadu terbutryny, który jest stosunkowo krótki w glebie, wynosząc 14 - 28 dni [28], natomiast znacznie dłuższy w osadach dennych, w których połowiczny zanik następuje w czasie 240 dni w osadach znajdujących się w stawach i 180 dni w osadach rzecznych (18].

Źródła zanieczyszczenia i drogi transportu ścieków opadowych w przypadku terbutryny są takie same, jak opisano w rozdziale 2.5 .

Mimo lepszej rozpuszczalności terbutryny w wodzie jej stężenie w spływie $\mathrm{z}$ fasad jest zbliżone do stężenia cybutryny w tych samych warunkach. Podczas badań przeprowadzonych w Szwajcarii [5] obserwowano stężenie terbutryny w odpływie z fasad zraszanych wodą opadową. Przy wstępnej zawartości terbutryny wynoszącej $1700 \mathrm{mg} \cdot \mathrm{m}^{-2}$ materiału fasady podczas pierwszego opadu stężenie terbutryny w odpływie wynosiło od 100 do $800 \mu \mathrm{g} \cdot \mathrm{l}^{-1}$. W odpływach powstających podczas kolejnych opadów obserwowano wykładniczy spadek stężenia terbutryny.

\section{Podsumowanie i wnioski}

Na podstawie przedstawionego przeglądu zagadnień związanych z występowaniem cybutryny (Irgarolu) w wodach przybrzeżnych można spodziewać się występowania podwyższonych wartości stężenia tego związku w polskich wodach przybrzeżnych, a szczególnie $w$ wodach portowych. Biorąc jednak pod uwagę czas, jaki upłynął od chwili wprowadzenia zakazu stosowania tego związku do ochrony kadłubów statków oraz uwzględniając mniejszy ruch jednostek (szczególnie jachtów) w polskich portach i marinach oznaczone wartości stężenia cybutryny powinny być niższe od podawanych we wcześniejszej literaturze wartości oznaczonych w portach zachodnioeuropejskich. Cytowane w artykule przykłady dowodzą jednak, że nie należy oczekiwać całkowitego wyeliminowania cybutryny z wód powierzchniowych. Na obszarach wód o zmiennej sezonowej intensywności ruchu jednostek pływających w Polsce można się spodziewać zróżnicowanych wartości stężenia cybutryny w okresie letnim i zimowym. Szczególnie dotyczy to jezior mazurskich. Ze względu na zastosowanie do ochrony fasad budynków cybutryna może powszechnie występować w środowisku, głównie w wodach, do których odprowadzane są ścieki miejskie. 
Dane literaturowe dowodzą, że także terbutryna bywa oznaczana w krajach Zachodniej Europy w wysokich wartościach stężenia w wodach powierzchniowych, a sposób jej występowania wskazuje na rolnicze pochodzenie zanieczyszczenia. W Polsce można się spodziewać możliwości wystąpienia podobnych przypadków. Przede wszystkim jednak należy brać pod uwagę występowanie terbutryny pochodzenia technicznego (wyeluowanej z materiałów budowlanych) w wodach powierzchniowych, do których odprowadzane są ścieki z obszarów zabudowanych.

\section{Literatura}

[1] Biselli S., Beste K., Huhnerfuss H., Fent K.: Concentrations of the antifouling compound Irgarol 1051 and of organotins in water and sediment of the German North and Baltic Sea Marinas. Marine Pollution Bulletin vol. 40, 2000, pp. 233243.

[2] Bohmont B.: The New Pesticide Users Guide. B \& K Enterprises. Fort Collins, CO, 1981.

[3] Bowman J.C., Readman J.W., Zhou J.L: Seasonal variability in the concentrations of Irgarol 1051 in Brighton Marina, UK; including the impact of dredging. Marine Pollution Bulletin, vol. 46, 2003, pp. 444-451.

[4] Buma A.G.J.: Impact of the antifouling agent Irgarol 1051 on marine phytoplankton species. Journal of Sea Research vol. 61, 2009. pp.133-139.

[5] Burkhardt M., Zuleeg S., Vonbank R., Simmler H., Lamani X., Bester K., Boller M.: Biocides in Facades Runoff and Storm Water of Urban Areas. $11^{\text {th }}$ International Conference on Urban Drainage, Edinburgh, Scotland, UK, 2008.

[6] Burkhardt M., Zuleeg S., Vonbank R., Schmid P., Hean S., Lamani X., Bester K., Boller M.: Leaching of biocides from façades materials to urban storm water runoff. Water Science and Technology vol. 63 no. 9, 2011, pp. $1974-1982$.

[7] Burkhardt M., Zuleeg S., Vonbank R., Bester K., Carmeliet J., Boller M., Wangler T.: Leaching of biocides from façades under natural weather condition. Environmental Science and and Technology vol. 66 no. 10, 2012, pp. 5497-5503.

[8] Dahl B., Blanck H.: Toxic effects of the antifouling agent Irgarol 1051 on the periphyton communities in coastal water microcosms. Marine Pollution Bulletin vol. 32, 1996, pp. 342-350.

[9] Dziennik Urzędowy Unii Europejskiej, L 226/1, 24.8.2013.

[10] Gatidou G., Thomaidis M.S., Zhou J.L.: Fate of Irgarol 1051, diuron and their main metabolites in two UK marine systems after restrictions in antifouling paints. Environment International vol. 33, 2007, pp. 70-77.

[11] Gough M.A., Fothergill J., Hendrie J.D.: A survey of southern England coastal waters for the s-triazine antifouling compound Irgarol 1051. Marine Pollution Bulletin vol. 28, 1994, pp. 613-620.

[12] Hall Jr. L.W., Anderson R.D., Ailstock M.S.: Chronic Toxicity of Irgarol 1051 to Submerged Aquatic Macrophytes. Final Report, University of Maryland, Wye, Research and Education Center, Queenstown, MD, 1999. 
[13] Hall Jr. L.W., Killen W.D., Anderson R.D., Balcomb R., Gardinalli P.: Ecological risk of Irgarol 1051 and its major metabolite in coastal California marinas and reference areas. Marine Pollution Bulletin vol. 58, 2009, pp 702 -710.

[14] Hoberg J.R.: Irgarol 1051 - Toxicity to a Marine Green Algae, Chlorococum sp., Report No. 98-2-7259, Springborn Laboratories, Inc., Wareham, MA., 1998a.

[15] Hoberg J.R.: Irgarol 1051 - Toxicity to a Golden Brown Algae, Isochrysis galbana. Report No. 98-2-2761, Springborn Springborn Laboratories, Inc., Wareham, MA, 1998 b.

[16] Hughes H.J., Alexander M.M.: The Toxicity of Irgarol 1051 to Navicula pelliculosa. Study ID B267-582-3, Malcolm Pirnie, Inc., Tarrytown, NY, 1993.

[17] Mohr S. et al.: Environmental concentrations and effects of Irgarol®. 4th SESSS, Brussels, SETAC Europe special Science Symposium 2011.

[18] Muir D.C.: Determination of terbutryn and its degradation products in water sediments, aquatic plants, and fish. J. Agr. Food Chem. 28, 1980, pp. 714-719.

[19] Nystrom B. Becker-Van Slooten K., Berard A., Grandjean D., Druart J-C., Leboulange C.: Toxic effects of Irgarol on phytoplankton and macrophytes in Lake Geneva, Water Research vol. 36 no. 8, 2002, pp. 2020-2028.

[20] Ormad M.P., Miguel N., Claver A., Matesanz J.M., Ovelleiro J.L.: Pesticides removal in the process of drinking water production. Chemosphere vol. 71, 2008, pp. 97-106.

[21] Quednow K., Puttmann W.: Monitoring terbutryn pollution in small rivers of Hesse, Germany. Journal of Environment Monitoring vol.12, 2007, pp. 1337-1343.

[22] Readman J.W.: Antifouling herbicides - a threat to the marine environment. Marine Pollution Bulletin vol. 32, 1996, pp. 320-321.

[23] Rufli H.: Report on the Algae Growth Inhibition Test with TK 13079. Project No. 874224, Ciba-Geigy Ltd., Basel, Switzerland 1988.

[24] Sargent C.J., Bowman J.C., Zhou J.L.: Levels of the antifoulant Irgarol 1051 in the Conwy Marina, North Wales. Chemosphere vol. 41, 2000, pp. 1755-1760.

[25] Scarlett A., Donkin M.E., Fileman T.W., Donkin P.: Occurrence of the marine antifouling agent Irgarol 1051 within the Plymouth Sound locality: implications for the green macroalga Enteromorpha intestinalis. Marine Pollution Bulletin vol. 34,1997, pp. 645-651.

[26] Schoknecht U., Gruycheva J., Mathies H., Bergmann H., Burkhardt M.: Leaching of biocides used in façade coatings under laboratory test condition. Environmental Science and Technology vol. 43 no. 24, 2009, pp. 9321-9328.

[27] Steen R.J.C., Leonards P.E.G., Binkman U.A.Th., Cofina W.P.: Ultratrace level determination of the antifouling agent Irgarol 1051 by gas chromatography with tandem mass spectrometric detection. Journal of Chromatography A vol. 766 no. 1 - 2, 1997, pp. 153-158.

[28] The Agrochemicals Handbook, Third Edition. Royal Society of Chemistry Information Systems, Unwin Brothers Ltd., Surrey, England, 1994.

[29] Thomas K.V., Fileman T.W., Readman J.W., Waldock M.J.: Antifouling paint booster biocides in the UK coastal environment and potential risks of biological effects. Marine Pollution Bulletin vol. 42, 2001, pp. 677-688. 
[30] Tolosa I., Readman J.W., Blaevoet A., Ghilini S., Bartocci J., Horvat M.: Contamination of Mediterranean (Cote d'Azur) coastal waters by organotins and Irgarol 1051 used in antifouling paints. Marine Pollution Bulletin vol. 32, 1996, pp. 335341.

[31] Urbanowicz J.: Występowanie chwastów w ziemniaku i metody ich zwalczania na terenie Polski. Biuletyn IHAR, nr 232, 2004, 185 - 191.

[32] U.S. Environmental Protection Agency. Fact Sheet Number 104: Terbutryn. U.S. EPA. Washington, DC, 1994.

[33] Velisek J., Sudova E., Machova J., Svobodova.: Effects of subhronic exposure to terbutryn in common carp (Cyprinuscarpio L.), Ecotoxicology and Environmental Safety, vol. 73, 2010, pp. 384-390.

[34] Vorkamp K.: New priority substances of the European Water Framework Directive: biocides, pesticides and brominated flame retardants in the aquatic environment of Denmark. Science of the Total Environment, vol. 470 - 471, 2014, pp. 459 -468 .

[35] Zhou J.L., Fileman T.W., Evans S,. Donkin P., Fauzi R., Mantoura C., Rowland S.J.: Seasonal distributions of the dissolved pesticides and polynuclear aromatic hydrocarbons in the Humber estuary and Humber coastal zone. Marine Pollution Bulletin vol. 32 no. 8 - 9, 1996, pp. 599-608.

\title{
CHARACTERISTICS AND OCCURRENCE OF CIBUTRINE AND TERBUTRINE IN WATER AND WASTEWATER
}

\begin{abstract}
S u m m a r y
According to directive 2013/39/EU list of priority substances was expanded with 15 new compounds, including biocides cibutrine and terbutrine. This way the range of substances obligatory monitored in water environment in EU countries will include new compounds. Cibutrine and terbutrine were not covered by state monitoring in Poland, therefore it is reasonable to review and collect literature informations on characteristics, application and presence of these substances in surface water environment in other countries. Both of these substances belong to triazine group and are the photosynthesis inhibitors. Besides of restrictions placed on their application in are still determined in water environment. The examples of this presence in inland surface waters and port waters were indicated. The possibility of wide presence of both compounds in Polish waters was indicated because of their application in buildings façades and roof coverings.
\end{abstract}

Keywords: biocides, algicides, herbicides, antifouling agents, surface water monitoring

Przestano do redakcji: 30.05 .2015 r.

Przyjęto do druku: 30.10 .2015 r.

DOI: $10.7862 / \mathrm{rb} .2015 .110$ 